Document downloaded from:

http://hdl.handle.net/10251/99174

This paper must be cited as:

Climente Alarcon, V.; J. Antonino-Daviu; Haavisto, A.; Arkkio, A. (2015). Diagnosis of Induction Motors Under Varying Speed Operation by Principal Slot Harmonic Tracking. IEEE Transactions on Industry Applications. 51(5):3591-3599. doi:10.1109/TIA.2015.2413963

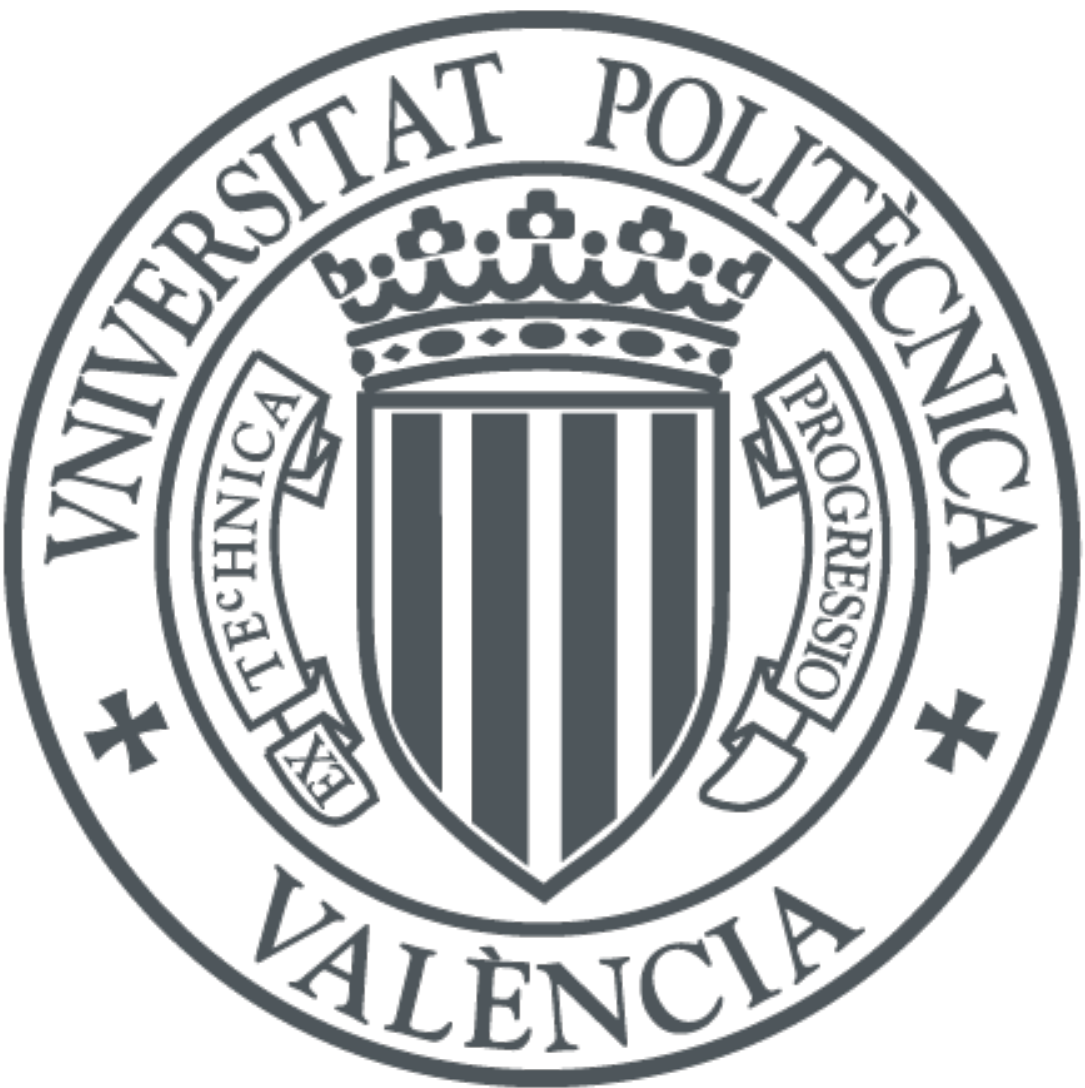

The final publication is available at

https://doi.org/10.1109/TIA.2015.2413963

Copyright Institute of Electrical and Electronics Engineers

Additional Information 


\title{
Diagnosis of Induction Motors under Varying Speed Operation by Principal Slot Harmonic Tracking
}

\author{
Vicente Climente-Alarcon, Member, IEEE, José A. Antonino-Daviu, Senior Member, IEEE, Ari \\ Haavisto, Antero Arkkio
}

\begin{abstract}
A detailed study on the energy content of a Principal Slot Harmonic (PSH) in an induction motor operating at variable slip is carried out. The machine is tested under different faulty conditions: broken rotor bar, mixed eccentricity and interturn short circuit. The use of a combined time-frequency analysis and particle filtering feature extraction procedure allows tracking the evolution of a PSH under different load profiles and integrate its energy. The proposed fault indicator provides values that are equivalent with the traditional one for stationary operation even in the case of pulsating load. The results show that the energy in the PSH reflects the overall state of the machine under these conditions. Furthermore, procedures for discerning the different faults in real applications are proposed.
\end{abstract}

Index Terms-- Fault diagnosis, induction motors, timefrequency analysis, variable load, Wigner-Ville Distribution, Principal Slot Harmonic.

\section{NOMENCLATURE}

bw Bandwidth.

$D_{k} \quad$ Measurement at time step $k$.

$f \quad$ Supply frequency.

$f_{r} \quad$ Rotational frequency.

$f_{R S H \pm n} \quad$ Frequency of the rotor slot harmonic $\pm n$.

$F \quad$ Magnetomotive force.

$k, m, n \quad$ Integer.

$p \quad$ Number of pole pairs.

$R \quad$ Number of rotor bars.

$s \quad$ Slip.

$t \quad$ Time.

$W_{x}(t, \omega) \quad$ Wigner-Ville Distribution.

$w_{k} \quad$ System noise at time step $k$.

$x_{k}(i) \quad$ Particle $i$ at time step $k$.

$x(t) \quad$ Signal (real or complex.)

$\theta \quad$ Angular position along the airgap

$\varphi \quad$ Phase.

$\phi \quad$ Flux.

$\Lambda$ Permeance.

$\tau \quad$ Delay.

$\omega \quad$ Angular supply frequency.

$\omega_{r} \quad$ Angular rotational speed.

V. Climente-Alarcon, A. Haavisto and A. Arkkio are with Departmen of Electrical Engineering and Automation, Aalto University, P. O. Box 13000, FI-00076 Aalto, FINLAND (e-mails: viclial@ieee.org, ari.haavisto@aalto.fi, antero.arkkio@aalto.fi)

J. Antonino-Daviu is with Instituto de Ingeniería Energética, Universitat Politècnica de València, Camino de Vera $\mathrm{s} / \mathrm{n}, 46022$, Valencia, SPAIN (phone: 0034-963877592; fax: 0034-963877599; e-mail: joanda@die.upv.es).

\section{INTRODUCTION}

I nduction motors constitute the mainstay of the industry due to their rugged construction, inexpensive manufacturing and easy maintenance. Their ubiquity has justified the development of diagnosis procedures with the aim of avoiding production disruptions. A relatively noninvasive method widely studied and applied in the last decades has been the Motor Current Signature Analysis (MCSA), which consists on establishing the severity of a fault by measuring the amplitude of specific fault components in the current spectrum of the machine [1].

Rotor Slot Harmonics (RSH) and among them the highest amplitude ones, known as the Principal Slot Harmonics (PSH), are components of the current and vibration spectra caused by the variations in the flux density along the air gap resulting from the discrete disposition of windings and difference in its permeability that the rotor bars produce. Therefore, these harmonics are generally inherent to the construction characteristics of the machine and can appear even in healthy state and under no load condition. Due to their high frequency, the mechanical effects (vibrations) of the flux density variations fall into the audible range, thus being the RSH initially studied during the designing stage of the machine in order to limit its noise level [2].

As new applications in devices such as machine-tools and robots required a higher accuracy in the operation of induction motors, the frequency assessment of the PSH became a competing procedure, along model based observers, for sensorless speed measurement $[3,4,5]$, since the frequency of these harmonics is proportional to the number of rotor bars and the slip, thus sharply reflecting any change in the turning rate caused by a varying load torque, which constitute a characteristic of this kind of machines. This facilitates the control of the motor, avoiding the introduction of additional sensors that reduce the overall reliability of the system.

In addition to designing and control, early works already identified their potential for diagnosis [6] that stems from the fact that the PSH result from the modulation of the stator winding magnetomotive force (MMF) by the air gap permeability and the rotor cage; thus combining the contribution of all these elements, and hence the effect of any fault on them. In this first study [6], the PSH were used to determine eccentricities, which appear when the rotating axis of the rotor does not coincide with the axis of the stator bore, generally as a result of load misalignment or bearing damage in a developed stage. For this case the variation of the air gap length modulates the PSH and, under certain conditions, sidebands are introduced in the stator current at a 
frequency equal to the rotational speed. This work was subsequently completed by Nandi et Al. that justified the appearance of further low frequency sidebands and established that, in order the PSH to be present in the current spectrum, the number of pole pairs of the flux density wave generated must equal the number of pole pairs produced by the stator winding $[7,8]$.

In this line, an additional early result showed the effect of interturn short circuits, a common fault usually caused by overvoltage, insulation ageing or end winding vibration on the axial leakage flux. With this objective the disturbance introduced in the stator MMF by the shorted turn was analytically propagated to the rotor showing that the RSH are affected [9].

More recent studies in the field of diagnosis have been focused on the Principal Slot Harmonics to carry out not only the especially difficult task of detecting static eccentricity $[10,11]$, but also broken bars $[12,13]$ and a combination of these faults [14] that causes a similar signature as mixed eccentricity. However, in most of these cases the current in stationary operation or during a locked rotor test is analyzed. Only [13] performs a transient study of the vibrations of a one pole pair motor subjected to a heavy startup.

Hence, this work combines both trends -harmonic tracking and diagnosis-, by exploring the use of the PSH as a mean to determine the state of a machine subjected to sharp slip variations as, for instance, it would be caused by intermittent loads. The approach followed in this case consist of extending the widespread Motor Current Signature Analysis applied in stationary operation (that is, the study of the frequency components in the current spectrum by means of the Fast Fourier Transform), to the now variable frequency harmonics. The traditional FFT analysis cannot be applied under these conditions since the energy of the fault component is spread in a bandwidth proportional to the speed variation range [15].

For this purpose, a combination of a time-frequency analysis and feature extraction method by means of Particle Filtering [16] is used. The developed method was originally conceived to track low frequency harmonics evolving around the main current component. However, in this work the utilization of Finite Impulse Response (FIR) filters, including advanced notch filters [17], and a higher sampling rate allows its application to the most demanding conditions that could be reproduced in a controlled manner in the laboratory, involving a pulsating load with PSH's frequency variations of up to $150 \mathrm{~Hz}$ per second [18].

For its validation, a wide experimental study has been carried out, in which the most important faults in induction machines: interturn short circuits, eccentricities and broken bars are studied, as well as a combination of several of them. The results show that the PSH, beyond constituting a way of measuring the changing speed of the machine, are also affected by all such defects, and hence provide a technique to ascertain its general health. Furthermore, the fluctuating amplitude of the PSH during the variable load cycle and the speed profile obtained might allow discerning kind of fault the machine is suffering.

With this aim, the paper is structured as follows: Section III presents the effect of the different faults in the PSH amplitudes, Section IV summarizes the data processing tools used, Section V shows the experimental procedure followed, and Sections VI and VII present the results and the conclusions, respectively.

\section{FAUlt EFFECTS ON THE PRINCIPAL SLOT HARMONICS}

This section provides the defining expressions of the principal slot harmonics and a summary, based on previous works by several authors, of how these components are affected by the different faults studied.

\section{A. Rotor slot harmonics on a healthy machine}

A general expression for the RSH can be obtained using the MMF-permeance wave approach, in which the flux density in the airgap is obtained as the multiplication of the magnetomotive forces of the rotor and stator and the air gap permeance (Fig. 1).

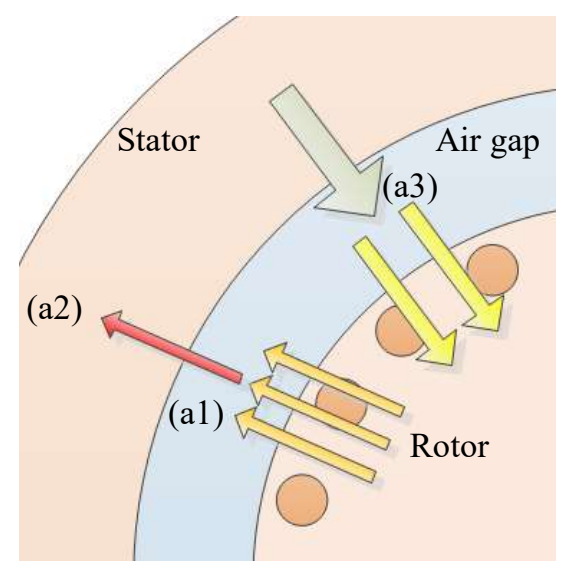

Fig. 1. The RSH arise as a consequence of the modulation by the passing rotor bars (a1) of the magnetic flux in the air gap. Depending on their wave number, these components can appear in the stator current (a2). Any further disturbance, such as a whirling rotor (a3), has its impact in this flux and hence may alter the RSH values.

The magnetomotive force due to the stator currents can be written as:

$$
\mathrm{F}_{S}(\theta, t)=\operatorname{Re}\left\{A \cdot e^{j\left(n_{1} \cdot \theta \pm \omega t\right)}\right\}
$$

This produces a flux density in the air gap referred to the rotor, assuming a smooth air gap with permeability $\Lambda_{0}$ as:

$$
\phi_{s r}(\theta, t)=\operatorname{Re}\left\{A \cdot \Lambda_{0} \cdot e^{j\left(n_{1} \cdot \theta^{\prime} \pm \omega_{r} t \pm \omega t\right)}\right\}
$$

The discrete distribution of the bars on the rotor cause a modulation of its magnetomotive force [7], yielding:

$$
\phi_{r r}(\theta, t)=R e\left\{A_{1} \cdot \Lambda_{0}^{2} \cdot e^{j\left(\left(R \pm n_{1}\right) \theta^{\prime} \pm n_{1} \omega_{r} t \pm \omega t-\varphi_{1}\right)}\right\}
$$

which referred to the stator is:

$$
\begin{aligned}
\phi_{r s}(\theta, t)=\operatorname{Re}\left\{A_{1}\right. & \cdot \Lambda_{0}^{2} \\
& \left.\cdot e^{j\left(\left(R \pm n_{1}\right)\left(\theta-\omega_{r} t\right) \pm n_{1} \omega_{r} t \pm \omega t-\varphi_{1}\right)}\right\}
\end{aligned}
$$

and then substituting the rotational speed by:

$$
\omega_{r}=\frac{1-s}{p} \cdot \omega
$$


the usual expression for the RSH is obtained:

$\phi_{r s}(\theta, t)=\operatorname{Re}\left\{A_{1} \cdot \Lambda_{0}^{2} \cdot e^{j\left(\left(R \pm n_{1}\right) \theta-\left(R \frac{1-s}{p} \pm 1\right) \omega t-\varphi_{2}\right)}\right\}$

Only if the number of poles $R \pm n_{l}$ coincides with the number of poles generated by the stator winding (1), given by the series:

$$
n=6 k \pm 1
$$

the RSH components will appear in the current spectrum. This result yields expression (19).

The highest amplitude ones whose frequency fulfills

$$
f_{R S H \pm n_{2}}=\left\{(k R) \frac{1-s}{p} \pm n_{2}\right\} f
$$

are known as the principal slot harmonics (PSH).

\section{B. Effect of faults on the PSH}

Given the fact that in the generation of the PSH there is a contribution of the main elements of the machine, it is reasonable to conclude that any change in their state will have an impact on these components:

1) Following [9], the effect in the air gap of the stator short circuit current can be modelled as a squareshaped magnetomotive force with a spatial distribution corresponding to the shorted turn's pitch superimposed to the one caused by a healthy winding. This adds further harmonics of the series:

$$
\mathrm{F}_{S_{-} s c}(\theta, t)=\operatorname{Re}\left\{A \cdot e^{j\left(n_{3} \cdot \theta \pm \omega t\right)}\right\}
$$

2) If a condition of mixed eccentricity exists, then the permeability is no longer constant, but fulfills the approximate expression:

$$
\Lambda \approx \Lambda_{0}+\Lambda_{1} \cdot \cos \theta+\Lambda_{2} \cdot \cos \left(\theta-\omega_{r} t\right)
$$

The modulation of (1) with the last two terms of expression (10) yields flux density waves with always the same number of pole pairs than the stator winding, thus inducing the well-known low frequency sidebands used to detect mixed eccentricity in the current spectrum at frequencies equal to $f_{\text {ecc }}=\left|f \pm k f_{r}\right|$.

These components now present in the stator in turn contribute to the appearance of further sidebands around the $\mathrm{RSH}$, in the form:

$$
\begin{aligned}
& \phi_{r s}(\theta, t) \\
& =\operatorname{Re}\left\{A_{2} \cdot \Lambda_{x} \cdot e^{j\left(\left(R \pm n_{1} \pm k_{1}\right) \theta-\left(\left(R \pm k_{2}\right) \frac{1-s}{p} \pm 1\right) \omega t-\varphi_{2}\right)}\right\}
\end{aligned}
$$

where $k_{1}=0,2$ and $k_{2}=0,1,2 \ldots$ for machines fulfilling (19). Clearly if $k_{l}=k_{2}=0$, the PSH components are affected by the mixed eccentricity condition.
3) Finally, the existence of a rotor bar disturbs the symmetry of the field in the air gap increasing the saturation of rotor and stator teeth, which reduces the torque for a given slip [20]. This defect is analytically modelled assuming a current across the faulty bar equal in magnitude to the healthy one but opposite in direction. A two pole magnetic field in the rotor is created, which increases the reluctances of stator and rotor teeth due to saturation, having a constant direction whose magnitude pulsates at the slip frequency $s \omega$. This can be decomposed, according to the doubly revolving field theory, in two rotational components of constant magnitude moving in opposite directions at a frequency equal to the pulsating field. The negative frequency one produces the known harmonics at twice the slip frequency $-2 s \omega$ traditionally used to diagnose the fault [13], whilst the positive sequence one rotates at the same speed $\omega$ of the fundamental wave, thus modifying its value.

\section{DATA PROCESSING METHOD}

In this Section, the data processing method used in this work and already presented in [16] is summarized. It consists of two stages, a time-frequency decomposition and feature extraction procedure.

\section{A. Time-frequency decomposition}

The Wigner-Ville distribution (WVD) is chosen for this task since it fulfills the marginals, that is, it correctly depicts the signal's energy on each time and frequency slice and features the high resolution needed to track fast varying harmonics [21, 22]. Mathematically it is computed by performing the Fourier transform with respect to the delay variable $\tau$ of the instantaneous autocorrelation (12) of a signal $x(t)$ :

$$
W_{X}(t, \omega)=\frac{1}{2 \pi} \int_{-\infty}^{\infty} x\left(t+\frac{\tau}{2}\right) \cdot x^{*}\left(t-\frac{\tau}{2}\right) e^{-j \omega \tau} d \tau
$$

In addition, the WVD first conditional moment with respect to the frequency (13) equals the instantaneous frequency (IF):

$$
\frac{d \varphi}{d t}=\langle\omega\rangle_{t_{k}}=\frac{1}{\left|x\left(t_{k}\right)\right|^{2}} \int_{-\infty}^{\infty} \omega W_{x}\left(t_{k}, \omega\right) d \omega
$$

Equations (12) and (13) enable the tracking of variable frequency fault harmonics in time-frequency boxes in which they prevail (isolated by notch and band pass filters), since under these conditions (chirp) the average obtained by (13) coincides with the frequency of this main contribution. An integration of the WVD value on a path centered in the IF gives an accurate computation of its energy $e_{I F, b w}$, avoiding the influence of noise or other weaker components:

$$
e_{I F, b w}=\sum_{t} \sum_{f_{b i n}=I F-b w / 2}^{I F+b w / 2} W_{x}\left(t, f_{b i n}\right)
$$


The bandwidth $b w$ can be easily determined experimentally for a given application as the one that maximizes the energy output.

Finally, as the Wigner-Ville distribution preserves the original energy of the signal, a fully equivalent fault indicator to the one generally used in the industry can be defined comparing this result with the energy of the current waveform $i_{c}$ :

$$
\gamma_{W}=10 \cdot \log \left[\frac{2 \sum_{t} i_{c}^{2}}{e_{I F, b w}}\right]
$$

It must be noted that another approach that uses distributions derived from the WVD is proposed in [23] for the industrially complex problem of differentiating eccentricity and load torque oscillation, which may be considered an extreme case of variable load operation.

\section{B. Feature extraction}

The addition of a feature extraction procedure after performing the time-frequency decomposition is justified by the appearance of oscillations known as cross terms in the WVD, as it can be appreciated in Fig. 2 for frequencies below $920 \mathrm{~Hz}$. In monotonic chirp-like evolutions the cross terms are minimal and the distribution works in its best conditions, however, even in time-frequency boxes in which only one component prevails, cross terms may appear as interferences between segments of the variable frequency harmonic [16].

The computation of the instantaneous frequency by (13) performs an averaging for each time instant $t_{k}$ that for signals including one main harmonic, gives a rough estimation of the frequency of that component. However, the IF oscillates rapidly and in order to avoid that, a low pass filter is used to smooth the result. This low pass filter adds a delay in the tracking that does not allow following rapid varying harmonics.

Therefore, in order to take advantage of the suitable characteristics of the WVD and avoiding the cross terms, a Particle filtering (PF) approach is applied to assess the instantaneous frequency of a PSH [16]. PF is a powerful method to estimate the Probability Density Distribution (PDF) of a system state $x_{k}$ given the measurements $D_{k}=\left\{y_{i}\right.$ : $i=1,2, \ldots k\}$ by a set of random samples $\left\{x_{k-1}(i): i=1,2, \ldots, N\right\}$ called particles, obtained from the PDF of $p\left(x_{k} \mid D_{k-1}\right)$ and propagated through the stages of prediction, update and resampling $[22,23]$.

In this approach, the PSH peak that appears at each time instant $t_{k}$ in the WVD is considered a target and the cross terms surrounding it, noise (Fig. 2a). For the prediction stage (b1) of the resulting bearings-only problem, a onedimensional second order model is utilized (16) to (18):

$$
\begin{gathered}
x_{k}=\left(\begin{array}{ll}
\frac{d \varphi}{d t} \quad \frac{d^{2} \varphi}{d t^{2}}
\end{array}\right)^{T} \quad w_{k}=\left(\begin{array}{ll}
w_{I F, k} & w_{d I F, k}
\end{array}\right)^{T} \\
x_{k}=\Phi x_{k-1}+w_{k} \\
\Phi=\left(\begin{array}{ll}
1 & 1 \\
0 & 1
\end{array}\right)
\end{gathered}
$$

where the system noise $w_{k}$, which accounts for the motorload inertia, is modelled experimentally as normal distributions whose standard deviations are 0.8 and 0.01 . The first value corresponds to the average difference in frequency for the newly generated particles in $\mathrm{Hz}$. Since this process is repeated as each new time-frequency slice becomes available, for the sampling rate used, the average variation is established empirically as $1 \mathrm{kHz} / \mathrm{s}$ or about 7 times the actual maximum variation of the harmonic measured. For the sake of stability the second coefficient, must be smaller, in this case two orders of magnitude. These values can be established theoretically from the expected loading torque for a determined machine. In the initial step the value of $p\left(x_{0}\right)$ is taken as the uniform distribution across the band pass.

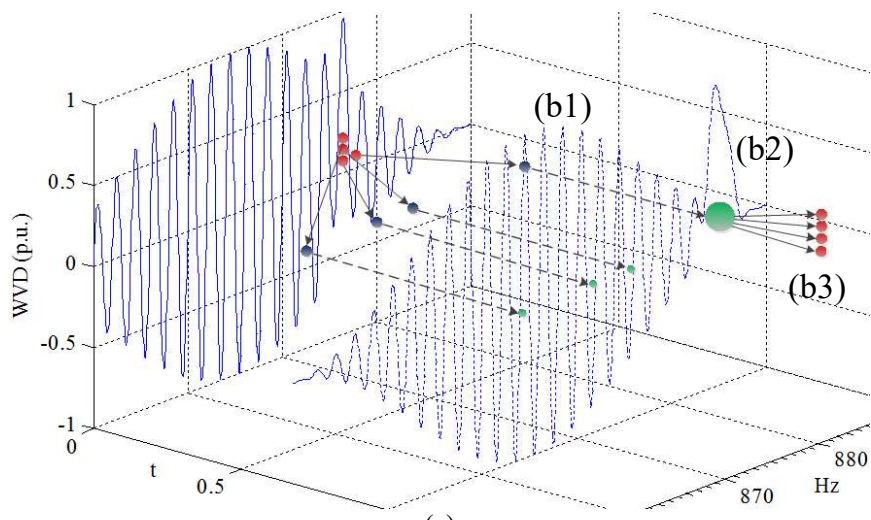

(a)

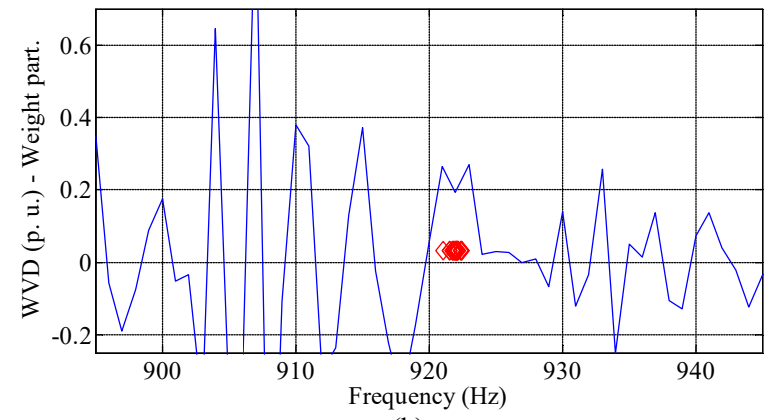

(b)

Fig. 2. a) Simulated tracking of a variable frequency harmonic by PF comprising the stages of prediction, b1; updating, b2 and resampling, b3. b) Measured WVD slice for a time instant showing the value of the distribution in frequency and the position and weight of the 30 particles after the resampling process (b3). Tracking of the PSH-1 during an interturn short circuit fault.

In the updating stage (b2), each newly computed slice of the WVD at time $t_{k}$ is treated as the PDF $p\left(y_{k} \mid x_{k}{ }^{*}\right)$ and the weight of the particles computed accordingly. The cross terms are rejected due to its oscillatory nature by taking for computation of the likelihood $p\left(y_{k} \mid x_{k}{ }^{*}\right)$ of the particles an average value of the spectrum on the surroundings of their position $( \pm 3 \mathrm{~Hz})$. A rounding to zero of the remaining negative values avoids the appearance of negative probabilities. Therefore, the particles will tend to gather around the locally averaged higher valued areas of the distribution, and their mean frequency, after the resampling process (b3), will indicate the frequency of the PSH (Fig 2a). In this sense, the procedure also performs an averaging, as the computation of the instantaneous frequency by (13), but in this case all the cross terms, weaker harmonics and noise 
are rejected. Fig. $2 \mathrm{~b}$ shows one slice of the WVD and the resampled particles gathering on the fault harmonic. Then, the energy present in the variable harmonic is computed integrating the value of the distribution using (13) along the path $I F$ determined by the particle filtering method.

\section{EXPERIMENTAL PROCEDURE}

For the experimental validation of the proposed approach, a two pole pair motor whose characteristics are shown in the Appendix, was tested in healthy, broken bar, mixed eccentricity and interturn short circuit conditions, as well as under combined broken bar and interturn shortcircuit and mixed eccentricity and interturn shortcircuit faults. In order to achieve the different states, three rotors (healthy, mixed eccentricity and one broken bar) were tested in the same stator. According to [7] the motor to be studied, will show PSHs in its current spectrum, even in the case of perfectly symmetrical feeding, due to featuring $R=40$ rotor bars, which fulfills the expression:

$$
R=2 p(3 m \pm r)
$$

where $p$ is the number of pole pairs, $m=0,1,2 \ldots$ and $r=0,1$.

The rotors were modified in the following ways: the broken bar fault was achieved by drilling one bar near its junction to the short circuit ring whilst the eccentricity was obtained by assembling a $\pm 0.4 \mathrm{~mm}$ eccentric sleeve between the shaft and the thickness-reduced inner ring of one bearing, causing a variation of the air gap of $57 \%$ at one end of the rotor. With this procedure, a dynamic eccentricity fault was created, however, due to constructive tolerances, all motors have also some static eccentricity, therefore, it can be considered that the machine was tested suffering a mixed eccentricity fault.

The stator, which had two parallel branches per phase, also featured two turns in one coil that could be short circuited, limiting the current by an external resistor of 3.6 $\Omega$. The short circuit current value at full load was $11.9 \mathrm{~A}$.

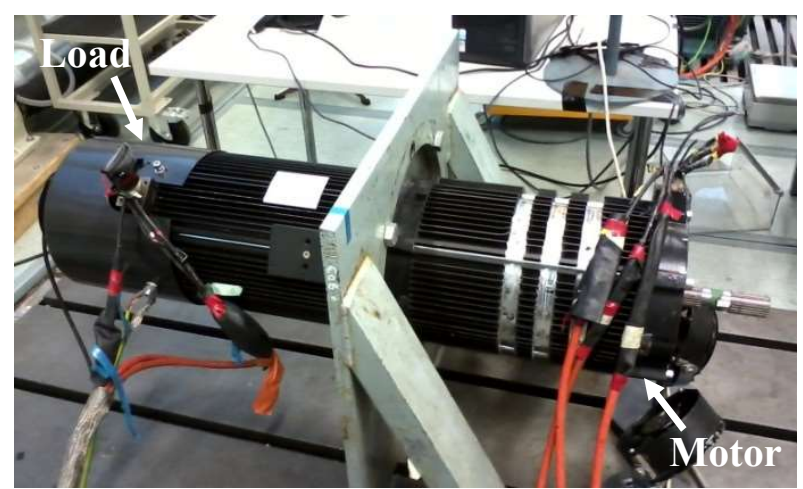

Fig. 3. Experimental test stand comprising two motors having the same characteristics coupled back-to-back.

A healthy motor of the same characteristics coupled backto-back to the first one and fed from an ABB ACSM1 inverter (Fig. 3) acted as load. The variable slip operation was achieved connecting the tested motor to the grid at 50 $\mathrm{Hz}$ and $300 \mathrm{~V}$, while the inverter feeding the load motor was commanded by a waveform generator running three kinds of cycles added to a common offset:
1) Sinusoidal wave having a period of 4 seconds and amplitudes of $50 \%, 75 \%$ and $100 \%$ (Fig. 5 a).

2) Sinusoidal wave having periods of 2 and 1 second with an amplitude of $100 \%$ (Fig. 5 b)

3) Square wave with periods of 2 and 1 second, and an amplitude of $100 \%$ (Fig. 5 c), yielding the fastest speed variations achievable in the test stand.

The slip change ranged between 3 and $8 \%$ which accounts to an estimated torque between 37 and $100 \mathrm{Nm}$. In this manner, controlled variable load profiles were achieved, allowing an easier comparison of the results among all states.

The diagnosis was carried out analyzing the current in one phase (Fig. 4), which was captured by a LEM LT 1005 current transducer and a shunt, yielding a total conversion ratio of $1 \mathrm{mV} / \mathrm{A}$. The current sensor had the following characteristics: primary nominal RMS current of $1000 \mathrm{~A}$, overall accuracy of $\pm 0.4 \%$, linearity $<0.1 \%$, response time $<1 \mu \mathrm{s}$ and frequency bandwidth up to $150 \mathrm{kHz}$. The lower short circuit current was acquired by the corresponding LEM LA 100-P device. A digital oscilloscope recorded the waveforms, as well as the rotational speed, with a sampling frequency of 5,000 samples/s and a resolution of 16 bits.

The tracking has been carried out on the PSH-1, which for this machine and under the load conditions of slip evolves between the limit frequencies of 860 and $950 \mathrm{~Hz}$.

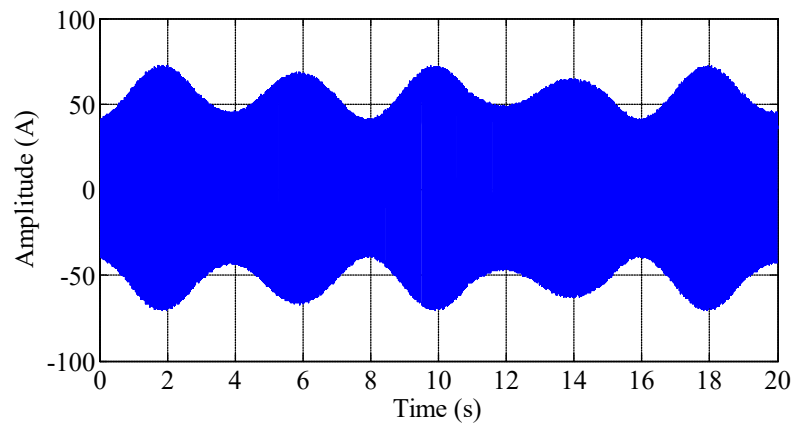

Fig. 4. Waveform captured during the variable load cycle: stator current of a motor having one broken bar.

\section{RESULTS AND DISCUSSION}

The results of applying the proposed approach to the tracking of the PSH-1 of the motor whose characteristics are presented in the Appendix are shown in this section.

For all the cases a pretreatment consisting of isolating a band between $860 \mathrm{~Hz}$ and $950 \mathrm{~Hz}$ has been used, prior to the computation of the analytical signal and the Wigner-Ville distribution. Instead of the IIR filters utilized in [16], in this work an advanced 270 tap notch FIR filter, based in [17], was utilized to remove the main current component, whereas two 400 tap high and low pass FIR filters tuned to the corresponding frequencies eliminated the rest of the harmonics present in the current spectrum. A downsampling has also been performed, featuring the time-frequency distribution a bandwidth of $1.25 \mathrm{kHz}$. For the tracking of the PSH component, the energy is integrated in a $3 \mathrm{~Hz}$ width band centered on its path. 


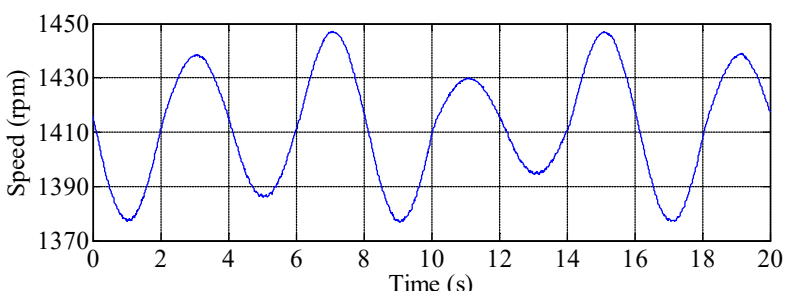

(a)

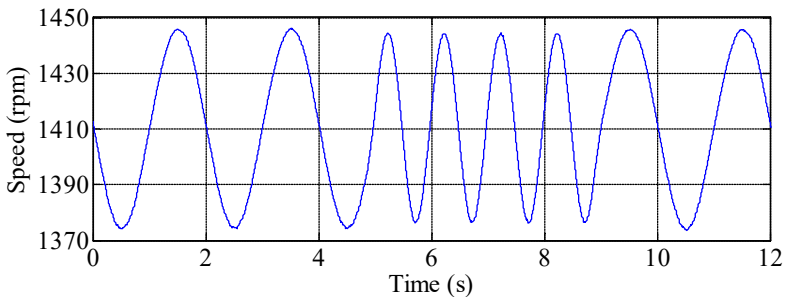

(b)

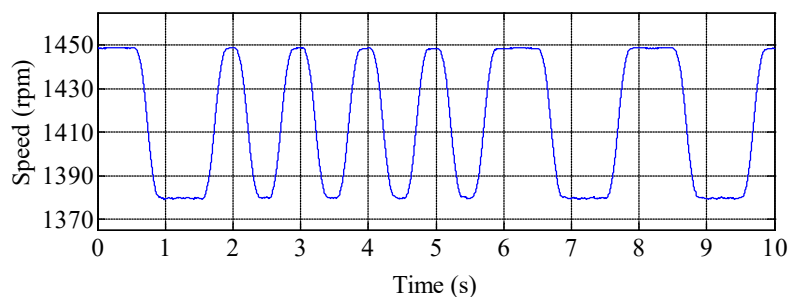

(c)

Fig. 5. Measured rotational speed of a motor having a broken bar under the three variable load cycles tested, (a) slow sinusoidal, (b) fast sinusoidal and (c) pulsating.

\section{A. Tracking of the Principal Slot Harmonic}

For the healthy state, Fig. 6 and 8 show the result of applying the developed procedure to the fastest evolving cycles programmed, that is, fast sinusoidal wave ("2") and pulsating wave (" 3 "). In both cases the method is able to partially track the PSH-1, even having such small amplitude (less than $60 \mathrm{~dB}$ ), as it is presented in Table I. Fig. 6 shows the WVD of the residual obtained from the filtering stage, for pulsating load, and the estimated frequency in white, which has been downsampled in the representation in order to allow showing the energy of the distribution beneath its path.

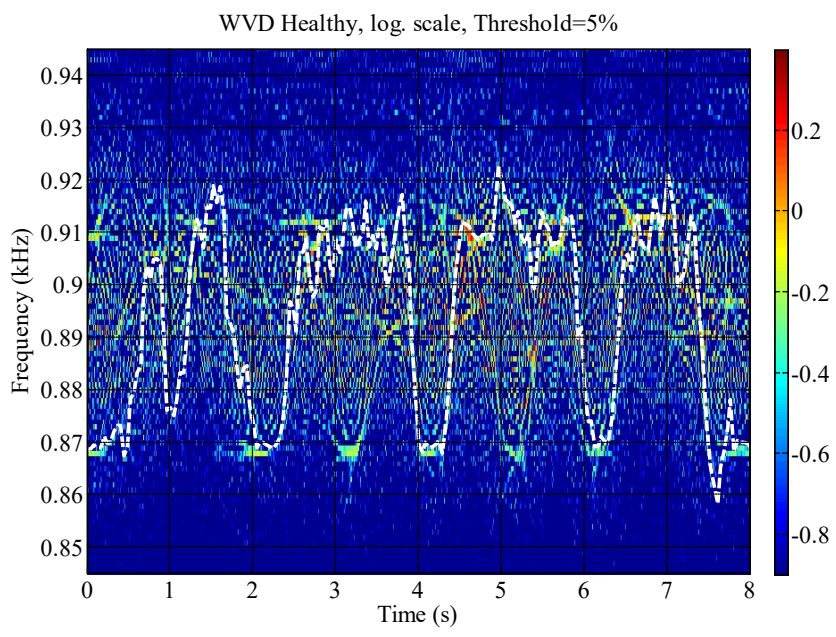

Fig. 6. WVD of residual obtained from the filtering stage, healthy motor under pulsating load. The estimated instantaneous frequency (downsampled) that partially tracks the Principal Slot Harmonic is represented by a white dashed line.
Fig. 7 presents the application of the proposed method to the tracking of the PSH-1 of the motor now suffering an interturn short circuit fault in the stator operating under pulsating load, that is, the most demanding conditions tested. In this case, and in spite of the light increase of energy detected, $0.9 \mathrm{~dB}$, and the sharp changes in the frequency of the Principal Slot Harmonic, of up to $150 \mathrm{~Hz} / \mathrm{s}$ that is, one order of magnitude more than what was achieved in [16], the Particle Filtering procedure tracks its evolution during the entire period, with negligible oscillations in the stages in which the speed of the machine remains constant, and completely rejecting the cross terms around and between the segments of the variable frequency harmonic.

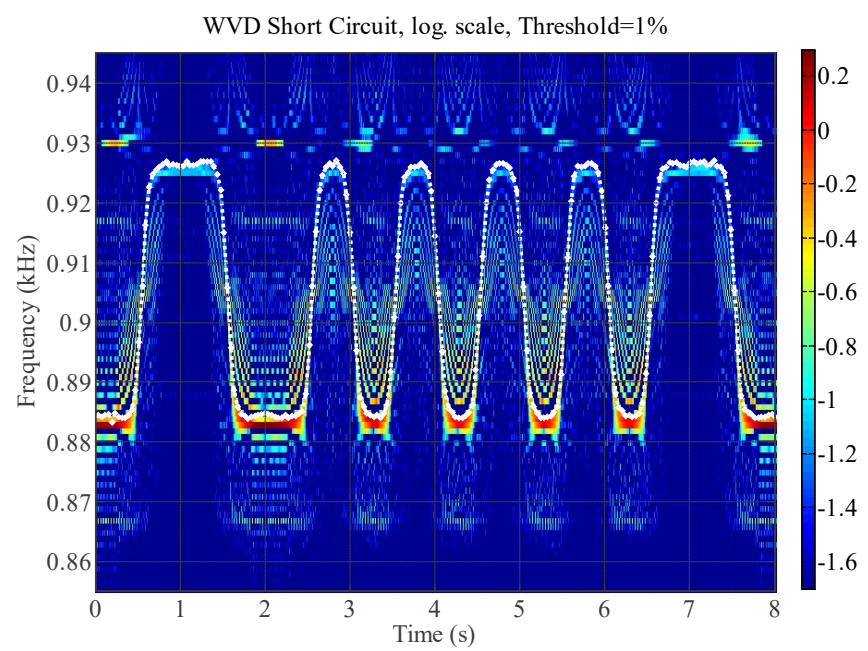

Fig.7. WVD of residual obtained from the filtering stage, motor having an interturn short circuit under pulsating load. The estimated instantaneous frequency (downsampled) that tracks the Principal Slot Harmonic is represented by white diamonds and dots.

Fig. 8 portrays again the result of the PSH tracking of a healthy machine, in this case operating under a fast sinusoidal load cycle. Only the time-frequency bins in which the energy has been integrated are depicted, giving an indication of what the algorithm identifies as the variable frequency harmonic. Segments of the actual evolution of the $\mathrm{PSH}$ are shown even in this difficult case in which the fault indicator features $62 \mathrm{~dB}$.

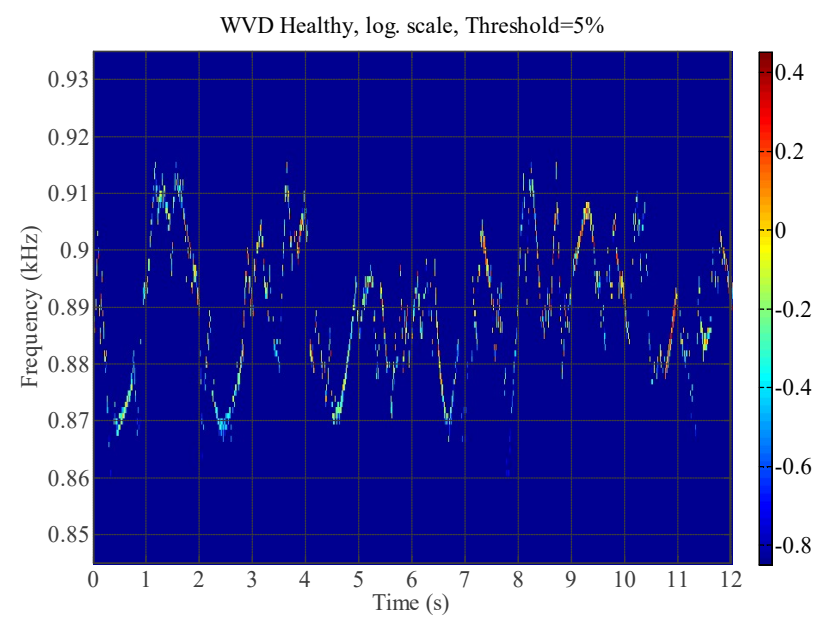

Fig. 8. Filtered WVD of a healthy motor under fast sinusoidal load. Only the frequency bins in which the energy has been integrated are shown. 
However, when current waveforms obtained from the motor suffering any defect or combination of them are analyzed, the algorithm tracks the PSH during its entire evolution and the quantification results indicate a clear increase in the energy detected (see Table I). For instance, Fig. 9 shows the filtered WVD of the motor now having a broken bar, operating under fast sinusoidal variable load. Only the time-frequency bins in which the energy has been integrated are shown.

The values of the quantification parameter (15) for healthy and faulty cases under each one of the variable load cycles shown in Fig. 5 are presented in Table I. In addition, the average FFT value of the PSH harmonic in the same slip range during stationary operation for the individual faults has been included for comparison. Compared to [16], in which IIR filters were used causing differences of more than $5 \mathrm{~dB}$, the application of the FIR filtering stage before the computation of the Wigner-Ville distribution slightly modifies the values obtained for variable load, attenuating them an average across the bandwidth of $0.42 \mathrm{~dB}$, well below the threshold needed to detect any of the studied faults. Therefore, this quantification parameter is fully equivalent to the stationary one, with the advantage that it can also be used in non-stationary operation.

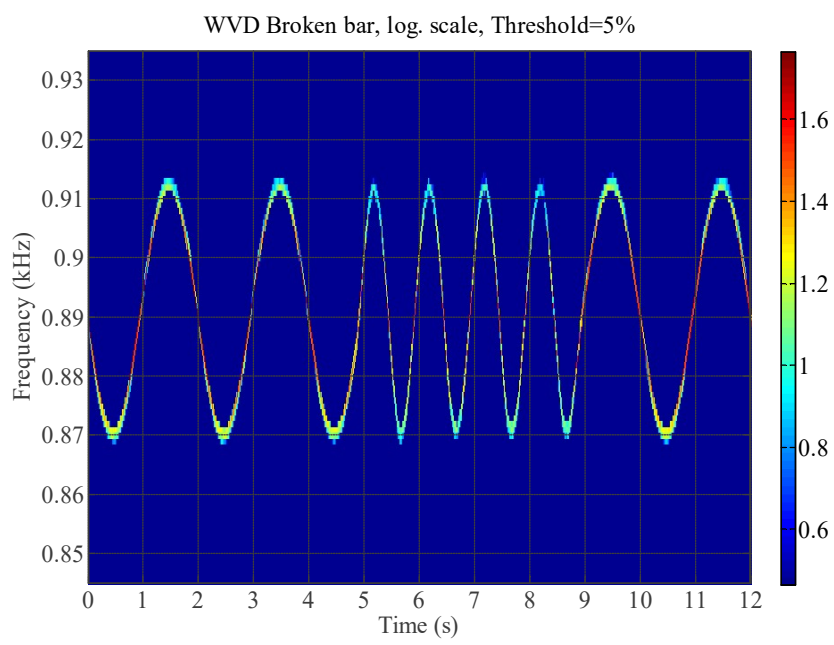

Fig. 9. Filtered WVD of a motor having a broken bar under fast sinusoidal load. Only the frequency bins in which the energy has been integrated are shown.

Table I indicates that faster variations of load between the same slip limits tend to slightly increase the energy present in the PSH for electrical asymmetries, whilst for mixed eccentricity the indicator evolves in the opposite way. In the combined cases, it remains almost constant, independent from the different speed profiles, but showing always a higher energy; therefore the short circuit fault has an additive effect.

Furthermore, when these results are compared to the equivalent indicators that study the low frequency sidebands, generally used for diagnosing rotor electrical and mechanical asymmetries during stationary operation, it is shown that the PSH-1 amplitude suffers a lower increase in the case of a broken bar (42 dB) [16]; but it is more sensitive to mixed eccentricities $(49 \mathrm{~dB})$. This yields for this particular machine and the severity of the faults studied similar values in those two cases.
TABLE I

PSH-1 BASED FAULT INDICATOR $\gamma_{\mathrm{w}}$ IN DB FOR EACH SPEED PROFILE

\begin{tabular}{ccccc}
\hline State & $\begin{array}{c}\text { Sinusoid. } \\
\text { 1 (Slow) }\end{array}$ & $\begin{array}{c}\text { Sinusoid. } \\
\text { 2 (Fast)* }\end{array}$ & Pulsat. * & Stationary \\
\hline Healthy & 62.2 & 62 & 61.4 & 63.5 \\
Broken bar & 46.5 & 46.1 & 46.2 & 46.5 \\
Eccentric. & 45.8 & 45.5 & 45.4 & 44.2 \\
$\quad \begin{array}{c}\text { Short } \\
\text { Circuit }\end{array}$ & 61 & 60.8 & 60.5 & 61.3 \\
$\begin{array}{c}\text { Broken bar } \\
\text { and SC }\end{array}$ & 46.1 & 45.9 & 46 & - \\
$\begin{array}{c}\text { Eccentric. } \\
\text { and SC }\end{array}$ & 45.1 & 44.9 & 44.9 & - \\
\hline
\end{tabular}

* The attenuation of the filters cause an average increase of $0.42 \mathrm{~dB}$ on the transient indicator compared with the stationary one.

\section{B. Energy distribution during the variable speed cycle}

In addition, the proposed method is able to display the evolving energy pattern integrated from the time-frequency distribution output (whose units, once normalized, are $\mathrm{A}^{2}$ $(\mathrm{Hz} \mathrm{s})^{-1}$ ), which may provide additional information. Fig. 9 shows the comparison of the PSH-1 energy content of the healthy motor and the same machine suffering different faults or combinations of faults under the fast varying pulsating load cycle (Fig. 5 c). First of all, it is patent the difference between the healthy case, in which background noise along with some parts of the harmonic are engaged and all the cases in which the machine was tested having a defect. The negative values of the energy, contributed by the cross terms and noise, in the first one constitute a clear sign that no component is being tracked. Under these circumstances, the average energy value for the entire cycle is negligible.
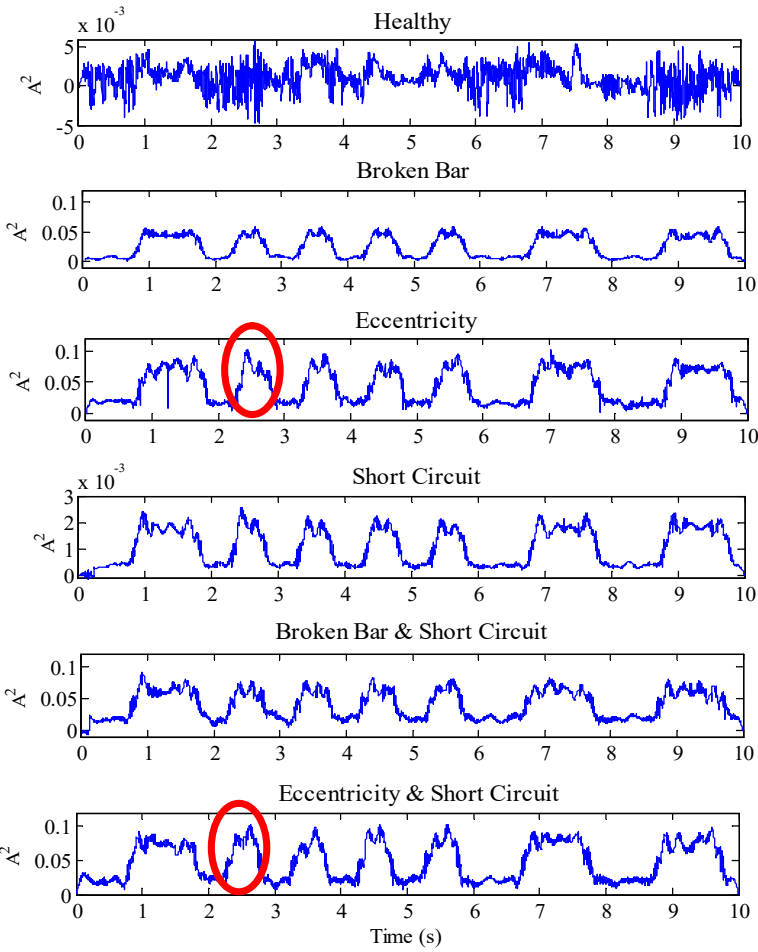

Fig. 10. Fault identification by energy profiles on an induction motor operation under load profile c). Electrical asymmetries cause a greater dependence of PSH-1 on load, whilst mixed eccentricity, for the same energy levels, introduces oscillations in the energy pattern (red circles). 
Nevertheless, when a fault exists, the algorithm accurately integrates the energy rejecting noise and cross terms, and hence the value remains positive during the entire evolution, no matter the sharpness of the speed variation.

Furthermore, in all the faulty cases the change in slip is reflected, with variations of around $80 \%$ in the energy detected as the current increases in the rotor bars.

The difference between rotor and stator faults is also well portrayed. The relatively minor interturn short circuit defect yields an energy pattern with similar shape but two orders of magnitude lower (also shown in Table I). The absolute values of energy for the combined cases also present a clear increase, damped the numerical value of the indicator by the use of a logarithmic ratio.

\section{On discrimination among different faults}

The data provided by the signal analysis method utilized in this work is ample, yielding two series of values: the PSH1 frequency and its energy versus time. Hence, several methods can be developed for discrimination among faults. The oscillations in the energy that appear on the segments with higher value in Fig. 10 (red circles) may be studied for this purpose. In addition, the torque yielded by the machine can be computed for each slip change, assuming constant loading cycle and temperature. Broken bars reduce the torque of the machine [20], whilst moderate eccentricities do not have such impact or even might increase it due to the tangential component of the unbalanced magnetic pull, depending on the connection of the stator winding.

\section{CONCLUSIONS}

This work studies the effect of several common faults in induction motors and combinations of some of them on the energy content of a Principal Slot Harmonic under three different variable load operation cycles. The method presented here can track and integrate its energy during the fastest speed changes achievable in the laboratory, yielding in those conditions a fault indicator fully comparable with the stationary one that reaches similar values. The results show that the PSH reflect the overall health of the machine, as well as provide an accurate measure of its rotational speed. For some applications, this would suffice to discern the kind of defect.

\section{APPENDIX}

The characteristics of the tested motor are: Star connected, rated frequency: $60 \mathrm{~Hz}$, rated voltage $\left(\mathrm{U}_{\mathrm{n}}\right)$ : 380 $415 \mathrm{~V}$, rated power $\left(\mathrm{P}_{\mathrm{n}}\right): 22 \mathrm{~kW}, 2$ pole pairs, stator rated current $\left(\mathrm{I}_{1 \mathrm{n}}\right): 41$ A rated speed $\left(\mathrm{n}_{\mathrm{n}}\right): 1700 \mathrm{rpm}$, number of rotor bars: 40 .

\section{REFERENCES}

[1] A. Bellini, F. Filippetti, C. Tassoni, G. -A. Capolino, "Advances in diagnostic techniques for induction machines," IEEE Trans. Ind. Electron., vol. 55, no. 12, pp. 4109-4126, Dec. 2008.

[2] W. R. Finley, M. M. Hodowanec, W. G. Holter, "An analytical approach to solving motor vibration problems Industry Applications," IEEE Trans. Ind. Appl., Vol. 36, No. 5, Sept/Oct 2000, Page(s): 14671480

[3] K. D. Hurst, T.G. Habetler, "A comparison of spectrum estimation techniques for sensorless speed detection in induction machines", IEEE Trans. Ind. Appl., Vol. 33 , No. 4, Jul/Aug 1997, pp. 898-905

[4] J. A. Restrepo, M. I. Gimenez, V.M. Guzman, J.M. Aller, A. Bueno, "Kernel selection for sensorless speed measurement of AC machines
(Wigner vs Page representation)," in Proc. IECON '98 24th Annual Conference of the IEEE Industrial Electronics Society, Vol. 2, Aug. 1998, Aachen, Germany pp. $991-996$

[5] A. Bellini, G. Franceschini, C. Tassoni, "Monitoring of induction Machines by maximum covariance method for frequency tracking", IEEE Trans. Ind. Appl., Vol. 42, No. 1, Jan/Feb 2006, pp. $69-78$

[6] J. R. Cameron, W. T. Thomson, A. B. Dow, "Vibration and current monitoring for detecting airgap eccentricity in large induction motors", IEE Proceedings, Vol. 133, Pt. B, No. 3, May 1986, pp. 155163

[7] Nandi, S., Ahmed, S., Toliyat, H.A., Mohan Bharadwaj, R. Selection criteria of induction machines for speed-sensorless drive applications IEEE Trans. Ind. Appl. Vol. 39, No. 3, 2003 , pp: 704 - 712

[8] J. Faiz, B. M. Ebrahimi, H. A. Toliyat, "Effect of Magnetic Saturation on Static and Mixed Eccentricity Fault Diagnosis in Induction Motor", IEEE Trans. Magn., Vol. 45, No. 8, August 2009, pp: 3137 - 3144

[9] J. Penman, H. G. Sedding, B. A. Lloyd, W. T. Fink, "Detection and location of interturn short circuits in the stator windings of operating motors," IEEE Trans. Energy Conv., Vol. 9 , No. 4, Dec 1994, pp. 652-658

[10] K. N. Gyftakis, J. C. Kappatou, "A Novel and Effective Method of Static Eccentricity Diagnosis in Three-Phase PSH Induction Motors," IEEE Trans. Energy Conv., Vol. 28, No. 2, Jun. 2013, pp. 405-412

[11] K. N. Gyftakis, J. C. Kappatou, "The zero-sequence current spectrum as an on-line static eccentricity diagnostic mean in $\Delta$-connected PSHinduction motors," in Proc. Diagnostics for Electric Machines, Power Electronics and Drives (SDEMPED), 2013 9th IEEE International Symposium on, 2013, Valencia, Spain pp. $302-308$

[12] A. Khezzar, M. Y. Kaikaa, M. El Kamel Oumaamar, M. Boucherma, H. Razik, "On the Use of Slot Harmonics as a Potential Indicator of Rotor Bar Breakage in the Induction Machine", IEEE Trans. Ind. Electron., Vol. 56, No. 11, Nov. 2009, pp. 4592-4605

[13] V. Climente-Alarcon, J. Antonino-Daviu, F. Vedreno-Santos, R. Puche-Panadero, "Vibration transient detection of broken bars by PSH sidebands", IEEE Trans. Ind. Appl., Vol. 49, No. 6, Nov/Dic 2013, pp. 2576-2582

[14] M.Y. Kaikaa, M. Hadjami, A. Khezzar, "Effects of the simultaneous presence of static eccentricity and broken rotor bars on the stator current of induction machine," IEEE Trans. Ind. Electron., Vol. 61, No. 5, May 2014, pp. 2452 - 2463

[15] Y. Gritli, S. B. Lee, F. Filippetti, L. Zarri, "Advanced Diagnosis of Outer Cage Damage in Double-Squirrel-Cage Induction Motors Under Time-Varying Conditions Based on Wavelet Analysis," IEEE Trans. Ind. Appl., Vol. 50, No. 3, May-June 2014, pp. 1791 - 1800

[16] V. Climente-Alarcon, J. A. Antonino-Daviu, Ari Haavisto, Antero Arkkio, "Particle Filter-based Estimation of Instantaneous Frequency for the Diagnosis of Electrical Asymmetries in Induction Machines," IEEE Trans. Instrum. Meas., Vol. 63, No. 10, 2014, Oct. 2014, pp. 2454-2463

[17] P. Zahradnik, B. Simak, and M. Vlcek, "Fast and robust analytical design of equiripple comb FIR filters for communication purposes," in Proc. $7^{\text {th }}$ ICN International Conference on Networking, Cancun, Mexico, 2008, pp. 588-593

[18] V. Climente-Alarcon, J. A. Antonino-Daviu, A. Haavisto, A. Arkkio, "Diagnosis of induction machines under varying speed operation by Principal Slot Harmonic tracking," in Proc. ICEM 2014 - 21th International Conference on Electrical Machines, Berlin, Germany, 2014.

[19] Burakov, A., Arkkio, A., "Comparison of the Unbalanced Magnetic Pull Mitigation by the Parallel Paths in the Stator and Rotor Windings," IEEE Trans. Magn., Vol. 43, No. 12, 2007, pp. 40834088

[20] J. Faiz, B.-M. Ebrahimi, “A New Pattern for Detecting Broken Rotor Bars in Induction Motors During Start-Up," Magnetics, IEEE Trans. Magn., Vol. 44, No. 12, Dec. 2008, pp. 4673-4683

[21] L. Cohen, Time-Frequency Analysis. A.V. Oppenheim, Ed. Prentice Hall Signal Processing Series, New Jersey, 1995.

[22] F. Auger, P. Flandirn, P. Gonçalvès, O. Lemoine, "Time Frequency Toolbox to Use with Matlab" CNRS (France) \& Rice University (USA) 1995-1996

[23] M. Blodt, D. Bonacci, J. Regnier, M. Chabert, J. Faucher, “On-Line Monitoring of Mechanical Faults in Variable-Speed Induction Motor Drives Using the Wigner Distribution", IEEE Trans. Ind. Electron., Vol. 55, No. 2, Feb 2008, pp. 522-533

[24] A. Doucet, N. de Freitas, N. Gordon, Sequential Monte Carlo Methods in Practice, Springer, 2001

[25] N. J. Gordon, D. J. Salmond, A. F. M. Smith, "Novel approach to nonlinear/non-Gaussian Bayesian state estimation", IEE Proceedings$F$, Vol. 140, No. 2, April 1993, pp. 107-113 